Article

\title{
Study of the Dielectric Properties of Artificial Sweat Mixtures at Microwave Frequencies
}

\author{
Angie R. Eldamak 1,2,*(D), Sarah Thorson ${ }^{2}$ and Elise C. Fear ${ }^{2}$ (D) \\ 1 Electronics and Electrical Communication Department, Faculty of Engineering, Ain Shams University, \\ Cairo 11517, Egypt \\ 2 Schulich School of Engineering, University of Calgary, Calgary, AB T2N1N4, Canada; \\ sarahgracethorson@gmail.com (S.T.); fear@ucalgary.ca (E.C.F.) \\ * Correspondence: angie.eldamak@eng.asu.edu.eg; Tel.: +2-010-2019-3779
}

Received: 17 April 2020; Accepted: 5 June 2020; Published: 9 June 2020

\begin{abstract}
Analysis of sweat is of interest for a variety of diagnosis and monitoring applications in healthcare. In this work, detailed measurements of the dielectric properties of solutions representing the major components of sweat are presented. The measurements include aqueous solutions of sodium chloride $(\mathrm{NaCl})$, potassium chloride $(\mathrm{KCl})$, urea, and lactic acid, as well as their mixtures. Moreover, mixtures of $\mathrm{NaCl}, \mathrm{KCl}$, urea, and lactic acid, mimicking artificial sweat at different hydration states, are characterized, and the data are fitted to a Cole-Cole model. The complex dielectric permittivity for all prepared solutions and mixtures is studied in the range of $1-20 \mathrm{GHz}$, at temperature of $23^{\circ} \mathrm{C}$, with ionic concentrations in the range of $0.01-1.7 \mathrm{~mol} / \mathrm{L}$.
\end{abstract}

Keywords: dielectric spectroscopy; dielectric properties; artificial sweat; sweat electrolytes; sweat monitoring; hydration monitoring

\section{Introduction}

With the increasing market in wearable devices, health monitoring, and preventive medicine, there is growing interest in analyzing properties of biofluids in the microwave frequency range. Dielectric properties of these fluids contribute to the understanding of microwave interaction with biological tissues [1,2] and allow identification of opportunities for disease detection and prevention [3-5]. This knowledge also contributes towards testing the impact of biofluids, specifically sweat, on health monitoring devices $[5,6]$ and consumer products $[7,8]$. Thus, accurate knowledge of dielectric properties of biofluids, specifically sweat, supports the design of new sensors, wearable devices, and therapeutic technologies.

Biofluids, including urine, blood, tears, and sweat, carry physiological biomarkers that can reflect health status $[5,6,9]$. Among the different biofluids, the composition of sweat and blood are osmotically related Tricoli et al. [5]. Although blood carries highly accurate information on the human body, sweat has the potential for easy, fast, and noninvasive monitoring Tricoli et al. [5].

Human sweat is composed of metabolites (uric acid, urea, and lactic acid), minerals (sodium, chloride, potassium, magnesium, zinc, iron, calcium, copper, and phosphate), as well as amino acids [3,5,9-14]. Among these components, tracking sodium $\left(\mathrm{Na}^{+}\right)$, chloride $\left(\mathrm{Cl}^{-}\right)$, and potassium $\left(\mathrm{K}^{+}\right)$can provide information on the water-salt balance in human tissues Romanov [4], hydration levels [11-20], and the presence of cystic fibrosis [3,5,21]. Properties of sweat in the microwave frequency range were reported in Romanov [4], which focused on comparing dielectric properties of sweat collected from different locations on the body. The work presented in Romanov [4] used an industrial phasometer to measure transmission magnitude and phase, which were used to calculate dielectric properties of sweat in the range of $300 \mathrm{MHz}$ to $3 \mathrm{GHz}$. 
Artificial sweat mixtures have been developed to mimic eccrine perspiration and used commercially to test consumer products such as bank cards, textiles, jewelry, and leather $[7,8]$. Other studies have used artificial sweat mixtures as test liquids when developing sensors [11-13]. Several technical associations have released different standards describing artificial sweat formulations [7,8,10-13]. From [7,8,10-13], the major components of artificial sweat are sodium chloride $(\mathrm{NaCl})$, potassium chloride $(\mathrm{KCl})$, urea, and lactic acid.

Several studies characterized the frequency-dependent properties of solutions of $\mathrm{NaCl}$ and $\mathrm{KCl}$ at different temperatures and concentrations from $100 \mathrm{kHz}$ to $40 \mathrm{GHz}$ in [1-3,11,22,23]. In Gulich et al. [1], Peyman et al. [2] and Nörtemann et al. [3], dielectric properties of $\mathrm{NaCl}$ and $\mathrm{KCl}$ solutions over the temperature range of $10-60{ }^{\circ} \mathrm{C}$ and concentration range of $0.001-5 \mathrm{~mol} / \mathrm{L}$ were presented in the band from $100 \mathrm{MHz}$ to $40 \mathrm{GHz}$. Moreover, the measurements in Peyman et al. [2] and Nörtemann et al. [3] were combined with literature values to derive empirical equations to describe the dielectric behavior of $\mathrm{NaCl}$ solutions using Debye and Cole-Cole models. In Lamkaouchi et al. [22], the permittivity of aqueous solutions of $\mathrm{NaCl}$ at millimeter wave bands of 37,89 , and $110 \mathrm{GHz}$ over the temperature range of $0-25{ }^{\circ} \mathrm{C}$ was also reported. The effect of temperature, pressure, and salt concentrations (up to $6 \mathrm{~mol} / \mathrm{L}$ ) on the permittivity of several aqueous salt solutions was examined in Maribo-Mogensen et al. [23]. The tested $\mathrm{NaCl}$ concentrations in Maribo-Mogensen et al. [23] are as high as 35\% and do not represent concentrations in biofluids. However, all data in Maribo-Mogensen et al. [23] refer to static permittivity and the effect of varying frequency was not studied. None of the reported studies examined the properties of mixtures or properties in the presence of other components of sweat, namely, urea and lactic acid. In Liu et al. [11], the conductivity of different concentrations of artificial sweat (14-262 mmol) was measured at different temperatures and at the single frequency of $100 \mathrm{kHz}$. The properties of urea in saline solutions were studied in the 1-14 GHz band in Jensen et al. [24] as a biomarker for dialysis treatment and kidney dysfunction. Electrical properties of lactate were reported in De los Reyes et al. [25] for agriculture applications.

Artificial sweat mixtures representing different hydration states were synthesized by our group in Eldamak et al. [26] to test an antenna-based sensor for noninvasive sweat monitoring. Electrical properties for artificial sweat mixtures representing normal and dehydrated sweat were reported in Eldamak et al. [26]. Although varying $\mathrm{NaCl}$ concentrations were tested, the impact of varying concentrations of other components of the artificial sweat solution was not explored in detail. This study presents the dielectric properties of aqueous solutions of the significant electrolytes in sweat, mixtures of these components, and artificial sweat mixtures representing normal and dehydration states. The dielectric properties are measured over the range of 1-20 GHz. This paper also explores the effect of $\mathrm{pH}$ level on electrical properties and provides Cole-Cole parameters for artificial sweat (normal and dehydrated concentrations) to fit measured data.

\section{Materials and Methods}

\subsection{Materials and Tested Solutions}

The preparations of artificial sweat (AS) follow the EN1811:2011 European Standard [8,10-13]. The initial recipe in Midander et al. [8] and Callewaert et al. [10] mimics human perspiration to test nickel release from jewelry as sweat can react with certain materials and trigger dermatitis nickel allergy or shorten product service life [7]. This recipe included $0.5 \% \mathrm{NaCl}, 0.1 \%$ urea, and $0.1 \%$ lactic acid dissolved in $1 \mathrm{~L}$ of distilled water. However, this recipe was modified in Liu et al. [11], Liu et al. [12] and Hoekstra et al. [13] to test sweat monitoring devices. Specifically, $0.1 \%$ potassium chloride $(\mathrm{KCl})$ was added to match the composition of human sweat reported in Liu et al. [12], Baker et al. [14] and Morgan et al. [15]. The modified recipe used in Liu et al. [11], Liu et al. [12] and Hoekstra et al. [13] was adopted in this paper.

The solution representing dehydrated sweat involved dissolving $85 \mathrm{mmol}$ of sodium chloride $(\mathrm{NaCl}), 13 \mathrm{mmol}$ of potassium chloride (KCl, Fisher Scientific), $17 \mathrm{mmol}$ of lactic acid (LD CARLSON 
Co., food-grade Lactic Acid 88\%), and $16 \mathrm{mmol}$ of urea (Jacquard, Commercial Grade) in $1 \mathrm{~L}$ of distilled water. For normal artificial sweat, the proportions of components were kept in the same ratios but the concentrations were one-tenth of those representing dehydration [11,24]. In addition, the $\mathrm{pH}$ level for all tested solutions was recorded using $\mathrm{pH}$ indicator paper with range of $0-14$. All concentrations were in $\mathrm{mol} / \mathrm{L}$. In addition to the artificial sweat mixtures, test solutions with different concentrations of $\mathrm{NaCl}, \mathrm{KCl}$, lactic acid, and urea and their mixtures were investigated. The single component solutions and mixtures explored in this study are presented in Tables 1 and 2, respectively. Table 1 summarizes single component solutions synthesized by dissolving the given amount of the tested component in $1 \mathrm{~L}$ of distilled water. Table 2 summarizes mixtures under test created by dissolving the given amounts of base and tested components in $1 \mathrm{~L}$ of distilled water. Properties of analyzed solutions were compared to distilled water. The focus was on concentrations in the range of $0.01-0.2 \mathrm{~mol}$, which is a common range among all tested components.

Table 1. Single component solutions under test (synthesized by dissolving in $1 \mathrm{~L}$ of distilled water).

\begin{tabular}{cccccc}
\hline Tested Component & \multicolumn{5}{c}{ Concentrations of Components (mol/L) } \\
\hline $\mathrm{NaCl}$ ("N") & 0.01 & 0.1 & 0.2 & 0.34 & 1.7 \\
$\mathrm{KCl}$ ("K") & 0.01 & 0.05 & 0.1 & 0.2 & \\
Lactic Acid ("L") & 0.02 & 0.06 & 0.12 & & \\
Urea (“U”) & 0.016 & 0.05 & 0.1 & 0.2 & \\
\hline
\end{tabular}

Table 2. Mixtures under test (synthesized by dissolving in $1 \mathrm{~L}$ of distilled water).

\begin{tabular}{|c|c|c|c|c|c|c|}
\hline \multirow{2}{*}{$\begin{array}{c}\text { Base Component } \\
\mathrm{K}=0.013 \mathrm{~mol}\end{array}$} & \multicolumn{6}{|c|}{ Concentrations of Tested Components (mol/L) } \\
\hline & $\mathrm{N}$ & 0.01 & 0.1 & 0.34 & 1 & 1.7 \\
\hline $\mathrm{N}=0.1 \mathrm{~mol}$ & K & 0.01 & 0.05 & 0.1 & 0.2 & \\
\hline $\mathrm{U}=0.016 \mathrm{~mol}, \mathrm{~L}=0.02 \mathrm{~mol}, \mathrm{~K}=0.013 \mathrm{~mol}$ & $\mathrm{~N}$ & 0.01 & 0.02 & 0.1 & 0.2 & \\
\hline $\mathrm{N}=0.1 \mathrm{~mol}, \mathrm{~L}=0.02 \mathrm{~mol}, \mathrm{U}=0.016 \mathrm{~mol}$ & K & 0.01 & 0.05 & 0.1 & 0.2 & \\
\hline $\mathrm{N}=0.1 \mathrm{~mol}, \mathrm{~K}=0.013 \mathrm{~mol}, \mathrm{U}=0.016 \mathrm{~mol}$ & $\mathrm{~L}$ & 0.02 & 0.06 & 0.12 & & \\
\hline $\mathrm{N}=0.1 \mathrm{~mol}, \mathrm{~K}=0.013 \mathrm{~mol}, \mathrm{~L}=0.02 \mathrm{~mol}$ & $\mathrm{U}$ & 0.016 & 0.05 & 0.1 & 0.2 & \\
\hline
\end{tabular}

\subsection{Measurement Setup}

All dielectric properties were measured using a dielectric probe and vector network analyzer (Agilent 87050E and E8364B, respectively), as well as the associated software as shown in Figure 1a. This technique is based on measuring reflection from an open-end coaxial probe immersed in the solution under test (SUT) [1,27]. Standard techniques were used to calibrate the measurement system and estimate complex permittivity from the reflection coefficient La Gioia et al. [27].

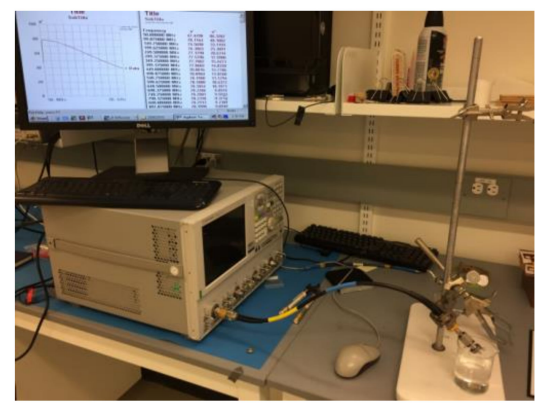

(a)

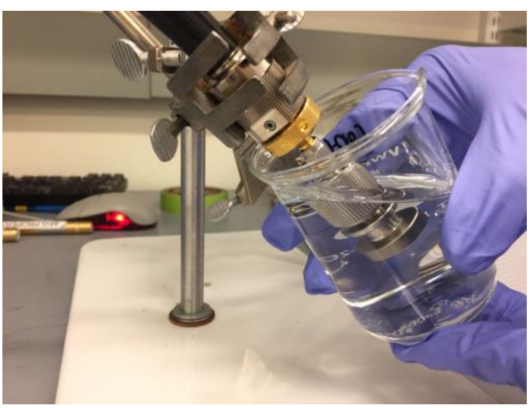

(b)

Figure 1. (a) Overall measurement setup including dielectric probe (87050E, Keysight Technologies), vector network analyzer (E8364B, Keysight Technologies), and solution under test (SUT) and (b) dielectric probe immersed in SUT. 
This frequency-dependent permittivity $\left(\varepsilon(\omega)^{*}\right)$ was estimated in the range of $1-20 \mathrm{GHz}$ at temperature of $23^{\circ} \mathrm{C}$. The frequency-dependent conductivity $(\sigma(\omega))$ estimates, representing losses in the solutions under test, were obtained from the complex permittivity using Equation (1):

$$
\varepsilon(\omega)^{*}=\varepsilon^{\prime}(\omega)-j \varepsilon^{\prime \prime}(\omega)=\varepsilon^{\prime}(\omega)-j \frac{\sigma(\omega)}{\omega \varepsilon_{0}}
$$

where $\omega$ is the angular frequency, the real and imaginary parts of the complex permittivity are denoted by $\varepsilon^{\prime}$ and $\varepsilon^{\prime \prime}$, respectively, and $\varepsilon_{\mathrm{o}}$ is the permittivity of vacuum. A $120 \mathrm{~mL}$ of sample of each prepared solution was measured using the set up shown in Figure 1. For each solution, three rounds of measurements were performed to minimize errors and confirm consistency. Each round involved collecting measurements at 400 equally spaced points from 1 to $20 \mathrm{GHz}$. The properties of each solution were estimated from the average of these three measurements. Each round involved also measuring properties of distilled water (DW) as a reference liquid.

\subsection{Validation of Measurements Using $\mathrm{NaCl}$ Aqueous Solutions}

To validate the measurements, solutions of $\mathrm{NaCl}$ with ion concentrations of $0.01-1.7 \mathrm{~mol} / \mathrm{L}$ were characterized in the range of 1 to $20 \mathrm{GHz}$. The recorded data at different concentrations were compared to published data in Gulich et al. [1] as shown in Figure 2. Our measurements for solutions of $\mathrm{NaCl}$ showed an increase of 3-5\% calculated over the band from 1 to $10 \mathrm{GHz}$ when compared to measured and fitted data at similar concentrations, temperature, and frequency range reported in Gulich et al. [1].

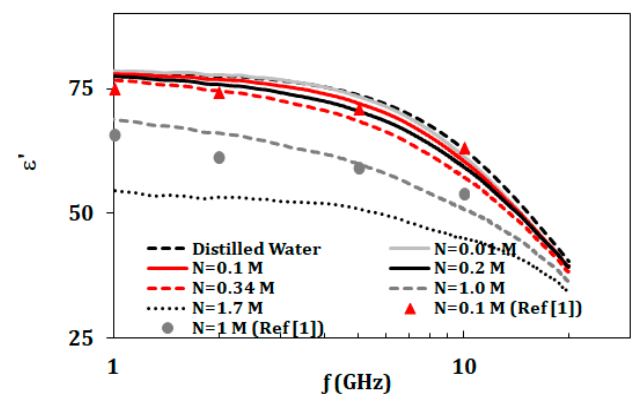

(a)

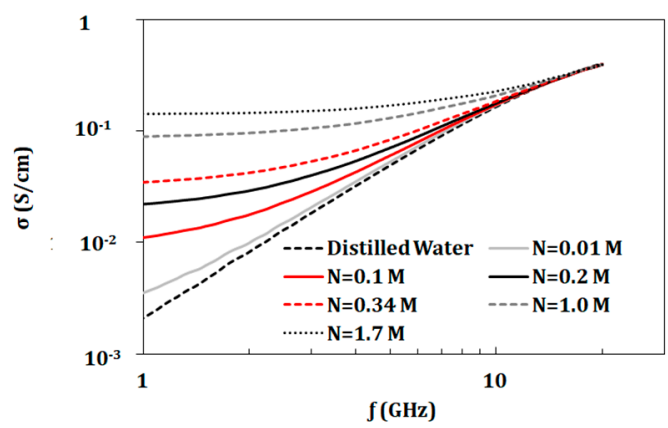

(b)

Figure 2. (a) Measured dielectric constant and (b) Measured conductivity for $\mathrm{NaCl}$ solutions at ion concentrations from 0.01 to $1.7 \mathrm{~mol} / \mathrm{L}$ at temperature $23^{\circ} \mathrm{C}$ in the range of $1-20 \mathrm{GHz}$ (" $\mathrm{N}$ " refers to $\mathrm{NaCl}$ and " $\mathrm{M}$ " refers to $\mathrm{mol} / \mathrm{L})$.

\section{Experimental Results}

\subsection{Single Component Solutions (KCl, Urea, and Lactic Acid)}

In this section, dielectric properties of solutions of $\mathrm{KCl}$, lactic acid, and urea (with concentrations given in Table 1) were investigated. Figures 2 and 3 present dielectric properties for $\mathrm{NaCl}, \mathrm{KCl}$, lactic acid, and urea compared to distilled water in the band of 1-20 GHz. Properties of $\mathrm{NaCl}$ solutions were recorded for the larger concentration range from 0.01 to $1.7 \mathrm{~mol}$. Other components were tested with concentrations up to $0.2 \mathrm{~mol}$ due to safety limitations. However, these solutions had concentrations of biological relevance. 

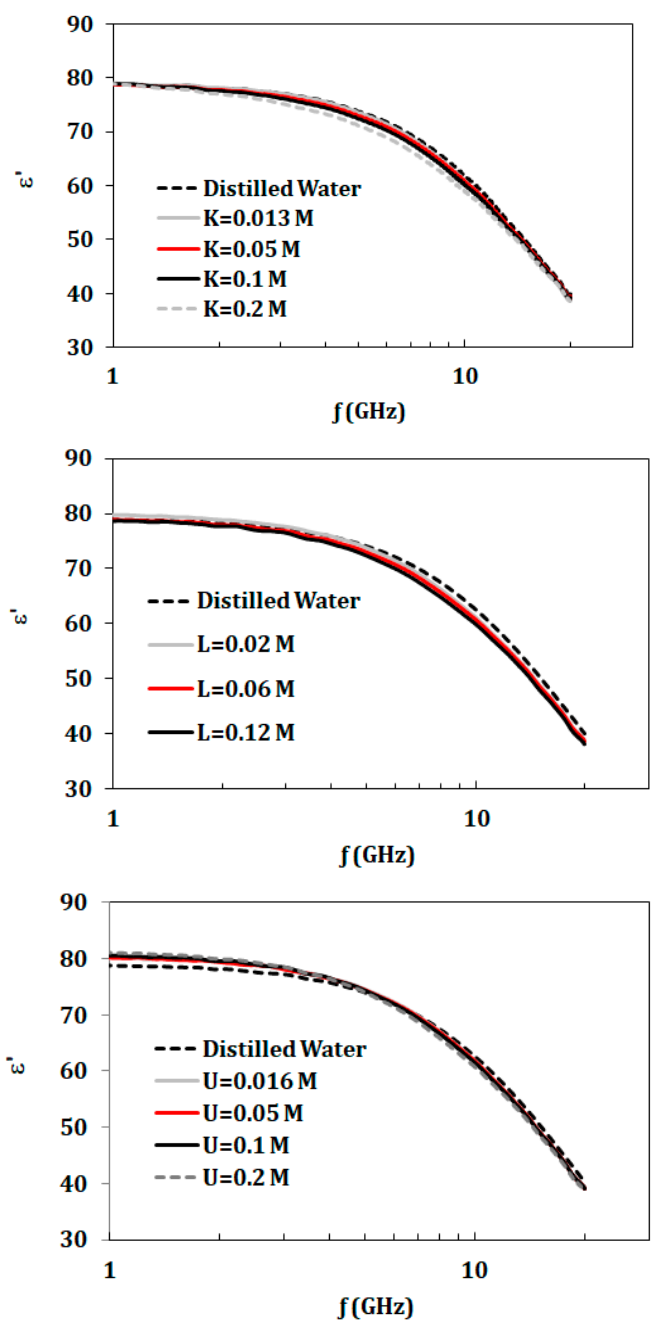

(a)
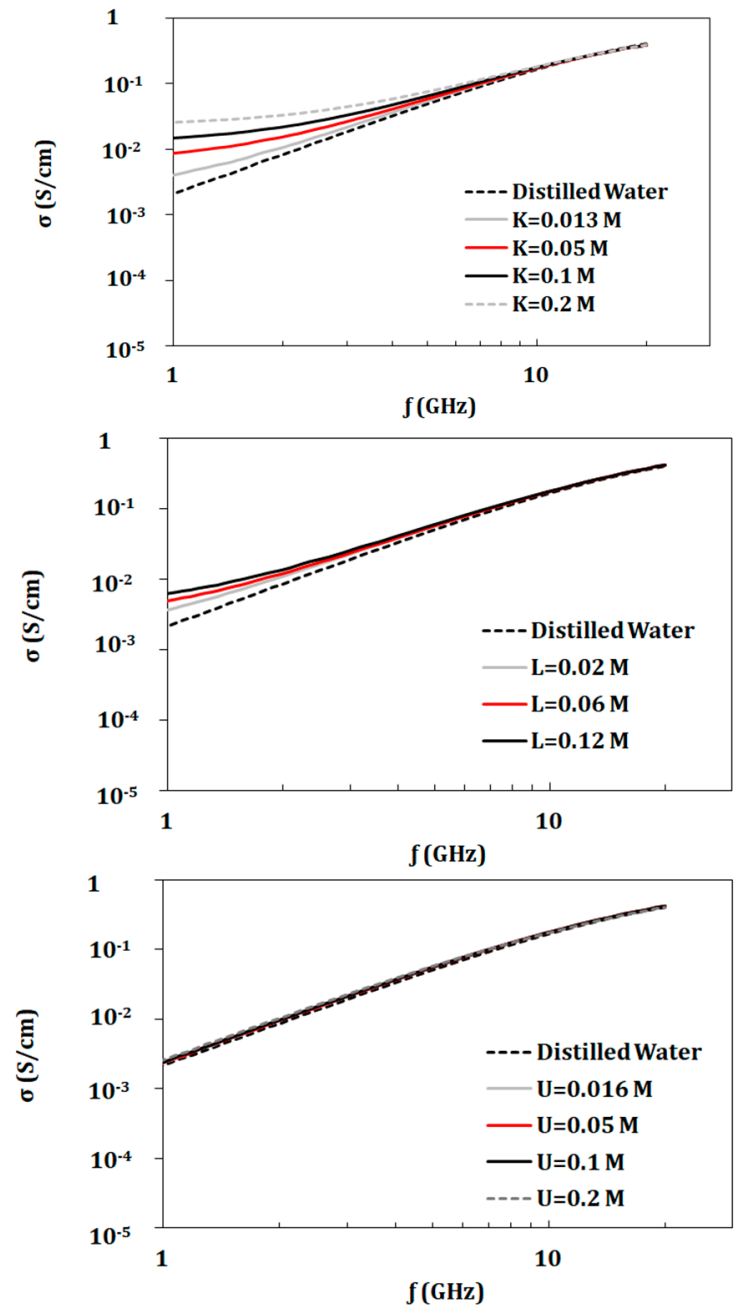

(b)

Figure 3. Measured dielectric properties for $\mathrm{KCl}$, lactic acid, and urea solutions at ion concentrations 0.01 to $0.2 \mathrm{~mol} / \mathrm{L}$ at temperature $23^{\circ} \mathrm{C}$ in the range of $1-20 \mathrm{GHz}$ : (a) dielectric constant and (b) conductivity. In all figures in this paper, " $\mathrm{K}$ " refers to $\mathrm{KCl}$, " $\mathrm{L}$ " to lactic acid, " $\mathrm{U}$ " to urea, and " $\mathrm{M}$ " refers to mol/L.

\subsection{Dual Component Solutions ( $\mathrm{NaCl}$ and $\mathrm{KCl}$ )}

For the given measurements shown in Figures 1 and 2, $\mathrm{NaCl}$ and $\mathrm{KCl}$ had greatest impact on complex permittivity ( $\varepsilon^{\prime}$ and $\left.\varepsilon^{\prime \prime}\right)$ and conductivity values. Thus, it is interesting to study mixtures of these two components. In this section, two groups of measurements were presented.

The first group starts with a KCL concentration of 0.013 mol (corresponding to dehydrated artificial sweat) to $1 \mathrm{~L}$ of distilled water. $\mathrm{NaCl}$ was added to this given solution in concentrations in the range of $0.01-1.7 \mathrm{~mol} / \mathrm{L}$ as shown in Table 2 . The second group had fixed $\mathrm{NaCl}$ concentration of $0.1 \mathrm{~mol}$ (corresponding to dehydrated artificial sweat), whereas $\mathrm{KCl}$ was added in the range of $0.01-0.2 \mathrm{~mol} / \mathrm{L}$ as shown in Table 2. Properties of both groups are presented in Figures 4 and 5. From measurements shown in Figure $4 \mathrm{a}$, with a base of $0.013 \mathrm{~mol} / \mathrm{L}$ of $\mathrm{KCl}$, the dielectric constant of mixtures did not showed significant change compared to distilled water until the $\mathrm{NaCl}$ concentration of $0.1 \mathrm{~mol} / \mathrm{L}$. Dielectric constant of solutions with a base of $0.1 \mathrm{~mol} / \mathrm{L}$ of $\mathrm{NaCl}$ showed changes starting at $\mathrm{KCl}$ concentrations of $0.05 \mathrm{~mol} / \mathrm{L}$ (Figure 5a). On the other hand, conductivity values were altered by adding either $\mathrm{KCl}$ or $\mathrm{NaCl}$ with concentrations as low as $0.01 \mathrm{~mol} / \mathrm{L}$ as shown in Figures $4 \mathrm{~b}$ and $5 \mathrm{~b}$. 


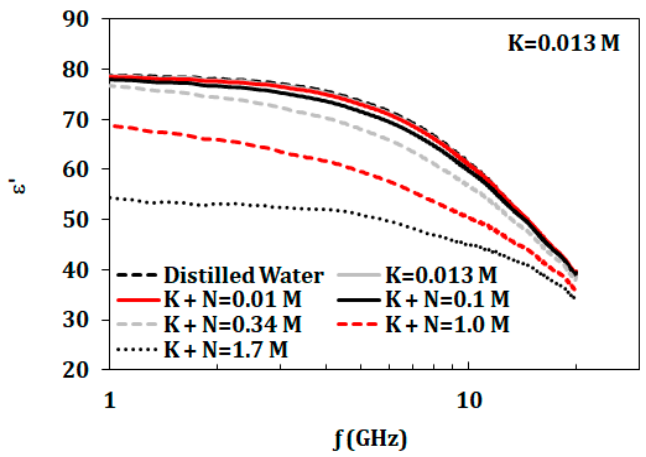

(a)

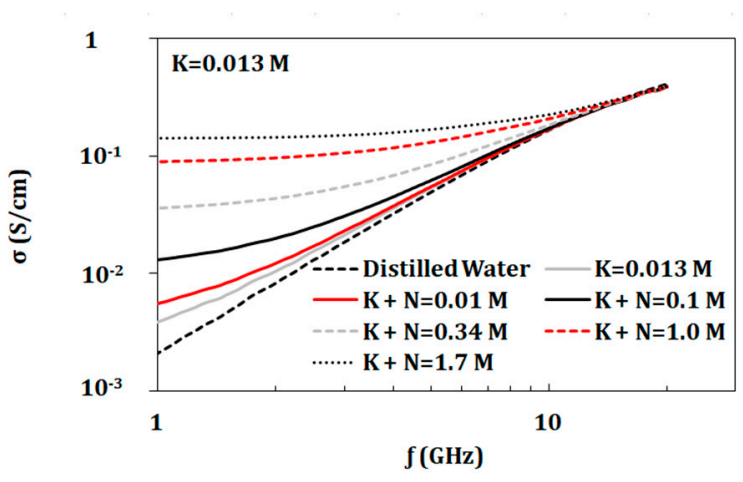

(b)

Figure 4. Measured dielectric properties for $\mathrm{NaCl}$ solutions at ion concentrations from 0.01 to 1.7 $\mathrm{mol} / \mathrm{L}$ and $\mathrm{KCl}$ with fixed concentration of $0.013 \mathrm{~mol} / \mathrm{L}$ at temperature $23{ }^{\circ} \mathrm{C}$ in the range of $1-20 \mathrm{GHz}$ : (a) dielectric constant and (b) conductivity ("M" refers to $\mathrm{mol} / \mathrm{L}$ ).

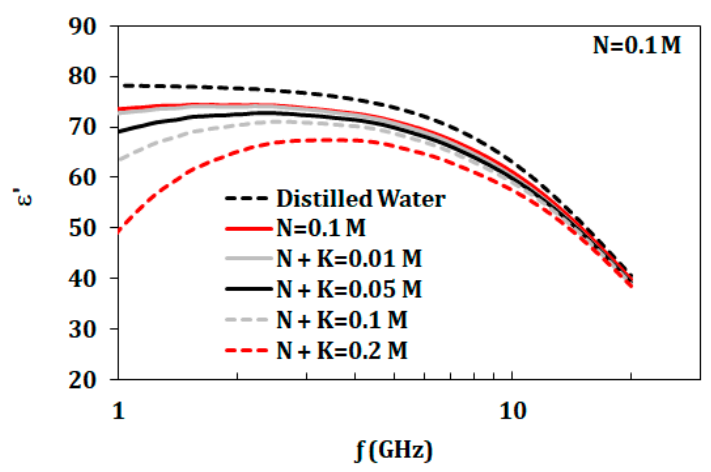

(a)

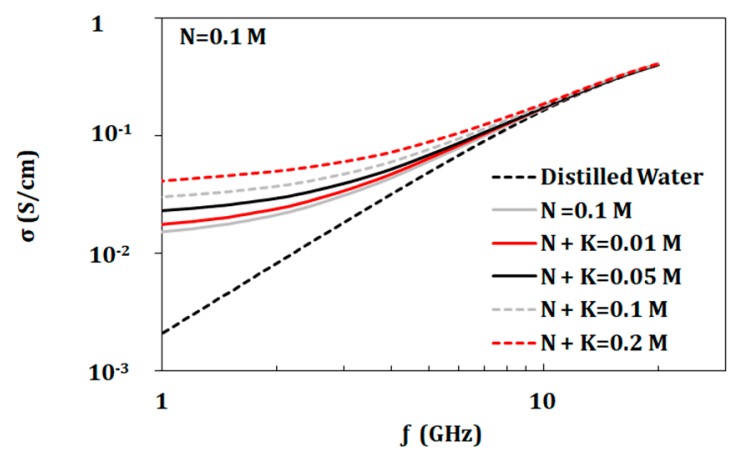

(b)

Figure 5. Measured dielectric properties for $\mathrm{KCl}$ solutions at ion concentrations from 0.01 to 0.2 $\mathrm{mol} / \mathrm{L}$ and $\mathrm{NaCl}$ with fixed concentration of $0.1 \mathrm{~mol} / \mathrm{L}$ at temperature $23{ }^{\circ} \mathrm{C}$ in the range of $1-20 \mathrm{GHz}$ : (a) dielectric constant and (b) conductivity ("M" refers to $\mathrm{mol} / \mathrm{L}$ ).

\subsection{Artificial Sweat Mixtures}

\subsubsection{Artificial Sweat Dielectric Properties}

In this section, dielectric properties of artificial sweat solutions were investigated. Artificial sweat samples with concentrations described in Section 2.1 were synthesized. Two concentrations were considered, representing sweat concentration for normal (termed diluted) and dehydrated individuals.

Table 3 shows values of complex permittivity $\left(\varepsilon^{*}=\varepsilon^{\prime}-\mathrm{j} \varepsilon^{\prime \prime}\right)$ and conductivity for artificial sweat mixtures and distilled water at $2.45 \mathrm{GHz}$. From measurements shown in Figure 6, the dielectric constant of diluted sweat with $0.01 \mathrm{~mol} / \mathrm{L}$ of $\mathrm{NaCl}$ was similar to distilled water in the $1-20 \mathrm{GHz}$ band. However, diluted sweat exhibited greater conductivity in the lower frequencies of the band compared to distilled water. On the other hand, dehydrated sweat with $\mathrm{NaCl}$ concentrations of $0.1 \mathrm{~mol} / \mathrm{L}$ showed distinct values for both dielectric constant and conductivity over the whole band. Moreover, the measured dielectric properties of the prepared artificial sweat mixtures showed similarity in values with those recorded for real sweat in Romanov [4].

Table 3. Electrical properties for distilled water (DW) and artificial sweat solutions at $2.45 \mathrm{GHz}$.

\begin{tabular}{cccc}
\hline Tested Solution & $\mathcal{\varepsilon}^{\prime}$ & $\mathcal{\varepsilon}^{\prime \prime}$ & $\boldsymbol{\sigma}$ \\
\hline Distilled water & 77.8 & 9.8 & 0.012599 \\
Diluted sweat $(13 \mathrm{mmol} / \mathrm{L})$ & 76.4218 & 11.2541 & 0.015295 \\
Dehydrated sweat $(131 \mathrm{mmol} / \mathrm{L})$ & 73.9557 & 20.29 & 0.03443 \\
\hline
\end{tabular}




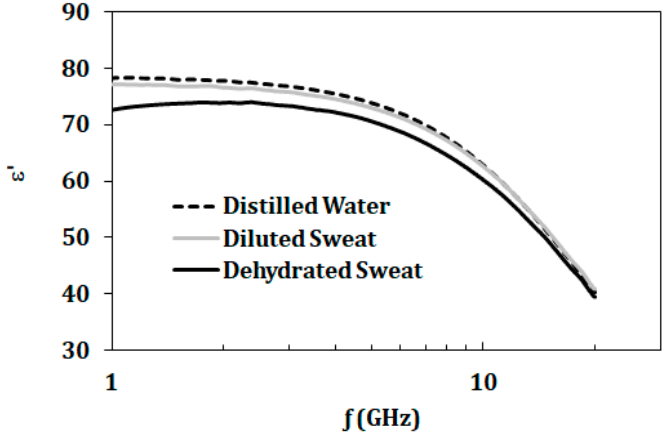

(a)

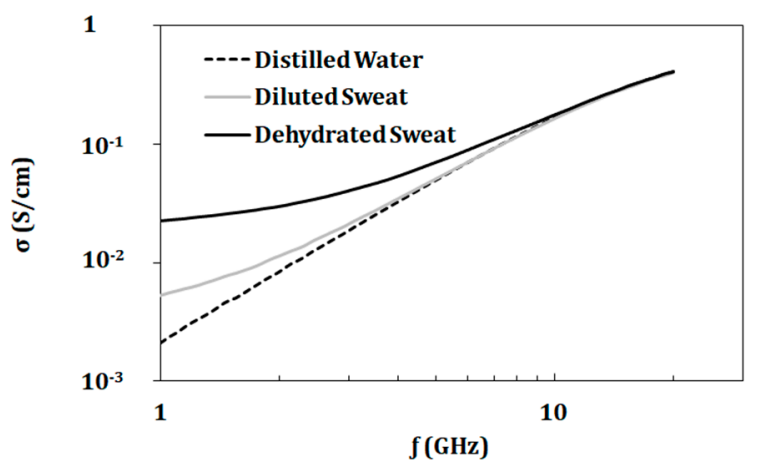

(b)

Figure 6. (a) Dielectric constant and (b) conductivity for distilled water (DW), diluted sweat $(0.05 \%$ $\mathrm{NaCl}, 0.01 \%$ for each urea, lactic acid, and $\mathrm{KCl})$, and dehydrated sweat $(0.5 \% \mathrm{NaCl}, 0.1 \%$ for each urea, lactic acid, and $\mathrm{KCl}$.

\subsubsection{Effect of $\mathrm{pH}$}

The proposed artificial sweat mixtures had measured $\mathrm{pH}$ level of 4 after adding the lactic acid. The $\mathrm{pH}$ level of this solution was not in the rated range for human sweat. Ammonia and sodium hydroxide were mentioned in the recipes reported in Midander et al. [8], Callewaert et al. [10] and Liu et al. [12] as a means of adjusting $\mathrm{pH}$ level of artificial sweat from 4 to 6.5. These additives are components of artificial sweat from a physiological point of view. In this work, $\mathrm{pH}$ was adjusted to 6.5 using sodium bicarbonate instead of ammonia or sodium hydroxide due to safety limitations. The dielectric properties of dehydrated sweat mixtures with $\mathrm{pH}$ level of 4 and 6.5 were recorded. Measurements showed maximum variations of $3 \%$ in dielectric properties for solutions with $\mathrm{pH}$ level 4 or 6.5 .

\subsubsection{Cole-Cole Model for Artificial Sweat Mixtures}

In this section, the measured frequency-dependent dielectric properties for artificial sweat mixtures representing normal and dehydrated states were fitted to a single pole Cole-Cole model as in Gulich et al. [1], Peyman et al. [2] and Nörtemann et al. [3]. The model is the sum of a relaxation function and a contribution from conductivity as presented in Equation (2) as:

$$
\hat{\varepsilon}=\varepsilon_{\infty}+\frac{\varepsilon_{\mathrm{s}}-\varepsilon_{\infty}}{1+(j \omega \tau)^{1-\alpha}}+\frac{\sigma_{\mathrm{i}}}{j \omega \varepsilon_{\mathrm{o}}}
$$

where, $\varepsilon_{\mathrm{S}}$ and $\varepsilon_{\infty}$ are limit of the permittivity at low and high frequencies, $\varepsilon_{0}$ is the permittivity of free space, $\tau$ is the relaxation time, $\alpha$ is the distribution parameter describing the symmetrical broadening of the relaxation loss peak, and oi is the ionic conductivity. The relaxation function describes the loss peak and the decrease in $\varepsilon^{\prime}$ Gulich et al. [1]. If $\alpha$ is set to 0 , the model is reduced to Debye model. Both Cole-Cole and Debye model were tested to fit the measured dielectric properties of artificial sweat in both diluted and dehydration states. However, with the given measurements $(1-20 \mathrm{GHz})$, Cole-Cole model was a better fit for the loss peak observed at higher frequencies. The deviation from the Debye model $(\alpha \neq 0)$ was connected with the correlations of the reorienting dipoles. According to the Jonscher's relationship, the alpha parameter reflects stronger long-time correlations.

Table 4 shows the calculated Cole-Cole model parameters for artificial sweat representing normal and dehydrated states, while Figure 7 shows the fitted data. $\varepsilon_{\infty}$ was calculated as 5.1398 using equation in Peyman et al. [2] and La Gioia et al. [27], which was a function of measurement temperature and concentration. 
Table 4. Cole-Cole parameters of artificial sweat mixtures obtained by fitting the experimental data collected from 1 to $20 \mathrm{GHz}$ and at $23^{\circ} \mathrm{C}$ to a Cole-Cole model.

\begin{tabular}{cccccc}
\hline Tested Solution & Concentration & $\varepsilon s$ & $\boldsymbol{\tau}$ & $\boldsymbol{\alpha}$ & $\boldsymbol{\sigma i}$ \\
\hline Diluted sweat & $13.1 \mathrm{mmol} / \mathrm{L}$ & 77.8 & $8.15 \mathrm{ps}$ & 0.005 & 0.31 \\
Dehydrated sweat & $131 \mathrm{mmol} / \mathrm{L}$ & 75.4 & $8.1 \mathrm{ps}$ & 0.015 & 1.53 \\
\hline
\end{tabular}

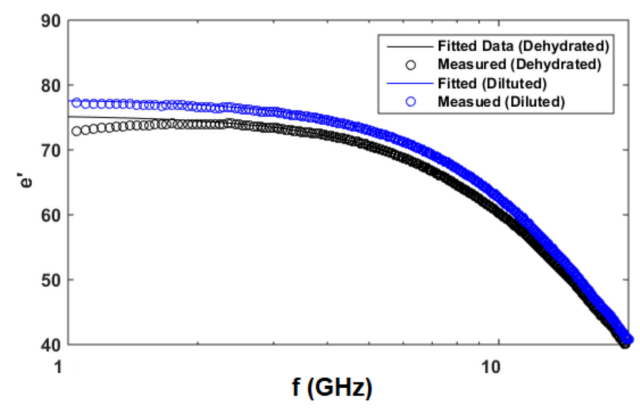

(a)

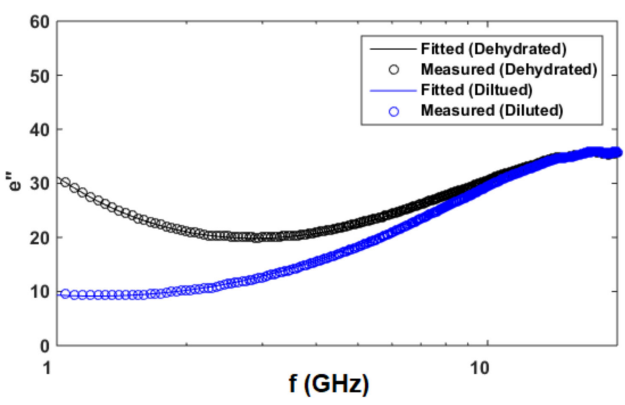

(b)

Figure 7. Measured and fitted: (a) real part of complex permittivity $\left(\varepsilon^{\prime}\right)$. (b) Imaginary part of complex permittivity $\left(\varepsilon^{\prime \prime}\right)$ for diluted artificial sweat $(0.05 \% \mathrm{NaCl}, 0.01 \%$ for each urea, lactic acid, and $\mathrm{KCl})$ and dehydrated artificial sweat $(0.5 \% \mathrm{NaCl}, 0.1 \%$ for each urea, lactic acid, and $\mathrm{KCl})$.

\subsubsection{Variation of Components Concentrations}

The artificial sweat mixture consists of $\mathrm{NaCl}, \mathrm{KCl}$, urea, and lactic acid. In this section, the effect of varying one component in the presence of the other three components was studied. The constant components are set at the concentrations appropriate for dehydrated sweat. The variable component is adjusted over the range of $0-0.2 \mathrm{~mol} / \mathrm{L}$. This range is chosen as it is common for all tested components. Figures 8 and 9 show the effect of varying $\mathrm{NaCl}$ and $\mathrm{KCl}$, respectively. Variations of lactic acid and urea were also tested in the range of $0-0.2 \mathrm{~mol} / \mathrm{L}$ in the presence of other three components where no changes were observed.

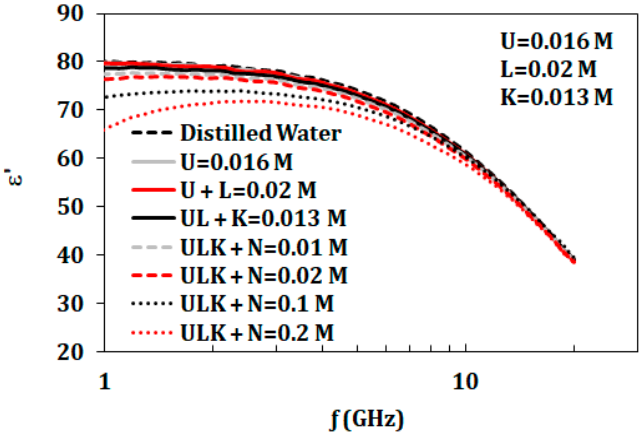

(a)

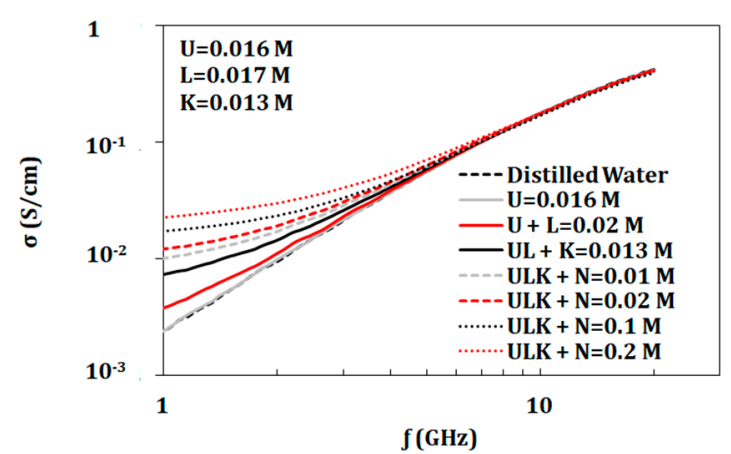

(b)

Figure 8. Measured dielectric properties for $\mathrm{NaCl}$ solutions at ion concentrations from 0.01 to $0.2 \mathrm{~mol} / \mathrm{L}$ with a base of $0.013 \mathrm{~mol} / \mathrm{L} \mathrm{KCl}, 0.016 \mathrm{~mol} / \mathrm{L}$ urea, and $0.02 \mathrm{~mol} / \mathrm{L}$ lactic acid at temperature $23^{\circ} \mathrm{C}$ in the range of 1-20 GHz: (a) dielectric constant and (b) conductivity(“ $\mathrm{M}^{\prime \prime}$ refers to $\mathrm{mol} / \mathrm{L}$ ). 


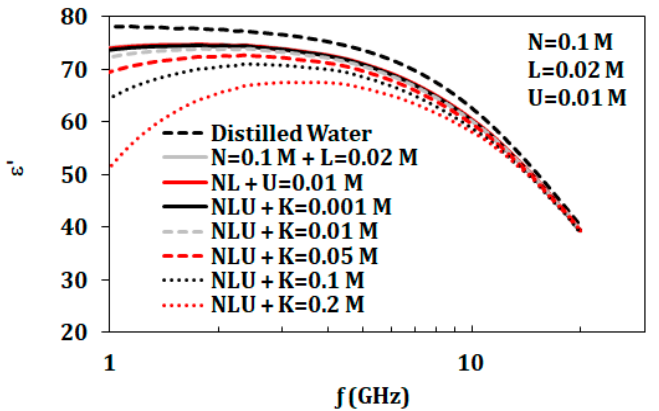

(a)

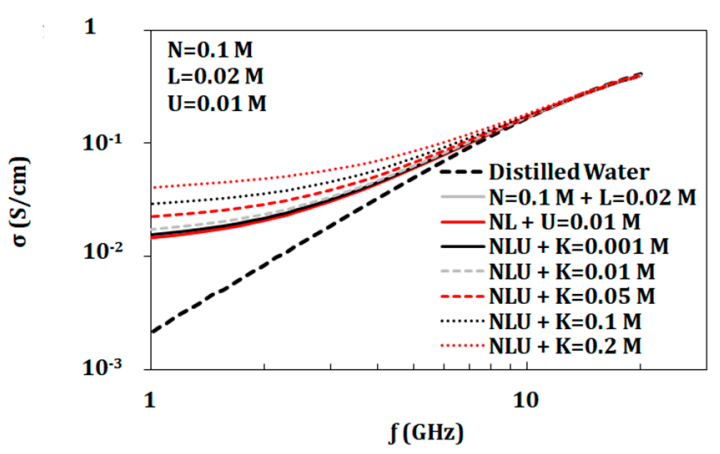

(b)

Figure 9. Measured dielectric properties for $\mathrm{KCl}$ solutions at ion concentrations from 0.01 to $0.2 \mathrm{~mol} / \mathrm{L}$ with a base of $0.1 \mathrm{~mol} / \mathrm{L} \mathrm{NaCl}, 0.016 \mathrm{~mol} / \mathrm{L}$ urea, and $0.02 \mathrm{~mol} / \mathrm{L}$ lactic acid at temperature $23^{\circ} \mathrm{C}$ in the range of 1-20 GHz: (a) dielectric constant and (b) conductivity ("M" refers to mol/L).

\section{Discussion}

In this paper, artificial sweat is prepared at concentrations representing different hydration states. Normal (termed diluted) and dehydrated sweat with overall concentrations of 13.1 and $131 \mathrm{mmol} / \mathrm{L}$, respectively, are synthesized and characterized in the range of $1-20 \mathrm{GHz}$. The measurements in Figure 6 show distinct values of dielectric properties at different hydration states. Changing $\mathrm{pH}$ level from 4 to 6.5 does not alter the electrical properties of prepared mixtures. Moreover, measured diluted and dehydrated artificial sweat samples are fitted to a Cole-Cole model with parameters shown in Table 4 . The measurements and models are useful tools for designing and testing sweat-based applications.

To explore the influence of components of the solutions, two sets of data are recorded and plotted in Figures 10 and 11. The given concentrations are chosen to represent different hydration states. To study the effect of changing concentration, properties of solutions at different concentrations are compared at $2.45 \mathrm{GHz}$. This is a frequency of operation for different wireless and sensing applications, as well as wearable devices [28-33]. The first set of data in Figure 10 presents the real and imaginary part of the dielectric constant of solutions formed from single components at $2.45 \mathrm{GHz}$. With these concentrations, Figure 10 shows that $\mathrm{NaCl}$ has the greatest effect on changing dielectric constant, followed by urea, $\mathrm{KCl}$, and lactic acid. On the other hand, $\mathrm{NaCl}$ has the greatest impact on varying conductivity, while urea has the least compared to distilled water values. The second set of data in Figure 11 shows comparison of dielectric properties (real and imaginary part at $2.45 \mathrm{GHz}$ ) for solutions of different mixtures of components with given range of concentrations shown in Table 5 .

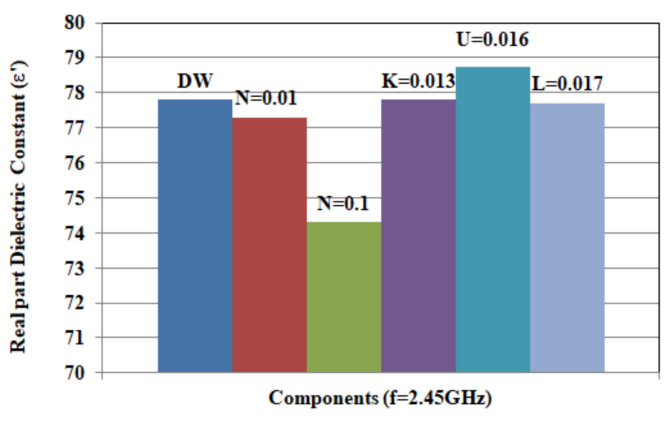

(a)

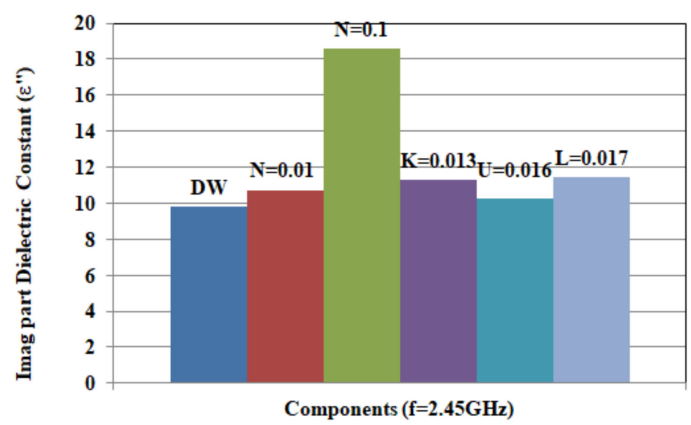

(b)

Figure 10. Measured complex permittivity: (a) real part $\left(\varepsilon^{\prime}\right)$ and (b) imaginary part at $2.45 \mathrm{GHz}$ for aqueous solutions of single component $(\mathrm{N}=0.01,0.1 \mathrm{~mol}, \mathrm{~K}=0.013 \mathrm{~mol}, \mathrm{~L}=0.017 \mathrm{~mol}$, and $\mathrm{U}=0.016 \mathrm{~mol})$. DW is distilled water. 


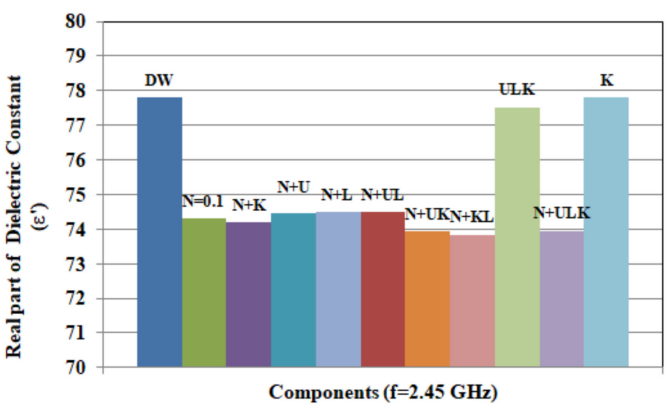

(a)

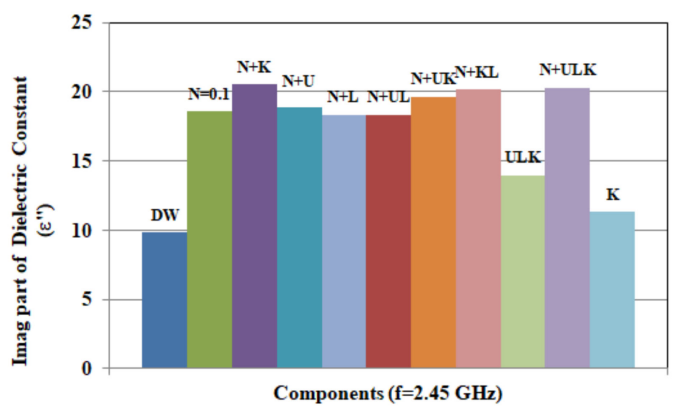

(b)

Figure 11. Measured complex permittivity: (a) real part $\left(\varepsilon^{\prime}\right)$ and (b) imaginary part at $2.45 \mathrm{GHz}$ Figure 6. $(\mathrm{N}=0.1 \mathrm{~mol}, \mathrm{~K}=0.013 \mathrm{~mol}, \mathrm{~L}=0.017 \mathrm{~mol}$, and $\mathrm{U}=0.016 \mathrm{~mol})$.

Table 5. Component solutions under test (synthesized by dissolving in $1 \mathrm{~L}$ of distilled water).

\begin{tabular}{c}
\hline Component $\mathbf{N}=\mathbf{0 . 1}$ mol, $\mathbf{K}=\mathbf{0 . 0 1 3} \mathbf{~ m o l}, \mathbf{U}=\mathbf{0 . 0 1 6} \mathbf{~ m o l}$, and $\mathbf{L}=\mathbf{0 . 0 1 7} \mathbf{~ m o l})$ \\
\hline Single component solutions: $\mathrm{N}=0.01 \mathrm{~mol}, \mathrm{~N}=0.1 \mathrm{~mol}, \mathrm{~K}, \mathrm{~L}, \mathrm{U}$ \\
\hline Dual component solutions: $\mathrm{N}+\mathrm{K}, \mathrm{N}+\mathrm{L}, \mathrm{N}+\mathrm{K}$ \\
\hline Three component solutions: $\mathrm{N}+\mathrm{KL}, \mathrm{N}+\mathrm{UL}, \mathrm{N}+\mathrm{KU}, \mathrm{UKL}$ \\
Four component solution: $\mathrm{N}+\mathrm{UKL}$ \\
\hline
\end{tabular}

The given results show that interaction between components forming mixtures could have an effect on determining the properties of the aqueous solutions. Dielectric properties of the mixture of urea, $\mathrm{KCl}$, and lactic acid are comparable to distilled water, however, change remarkably by adding $0.1 \mathrm{~mol} / \mathrm{L}$ of $\mathrm{NaCl}$. On the other hand, urea, lactic acid, and the combination of lactic acid and urea slightly increase dielectric constant of aqueous solution of $0.1 \mathrm{~mol} / \mathrm{L} \mathrm{NaCl}$.

As for conductivity, $\mathrm{NaCl}$ solutions and the dual solution of $\mathrm{NaCl}$ and $\mathrm{KCl}$ have the highest values.

However, when $\mathrm{NaCl}$ is mixed with urea, lactic acid, or combination of both, the mixture of urea, lactic acid, and $\mathrm{KCl}$ shows higher conductivity values compared to single component solutions ( $\mathrm{K}$, $\mathrm{L}$, and $\mathrm{U}$ ). However, the conductivity is still lower than $0.1 \mathrm{~mol} / \mathrm{L}$ solution of $\mathrm{NaCl}$. To validate the given results, solutions of single and combined components are also characterized at 1, 5, and $10 \mathrm{GHz}$. The recorded data are compared to results at $2.45 \mathrm{GHz}$. Measurements of permittivity and conductivity at different frequencies show similar variations to those at $2.45 \mathrm{GHz}$.

Further analyses for changing $\mathrm{NaCl}$ and $\mathrm{KCl}$ concentrations in the presence of other components are presented in Figures 12 and 13. Figure 12 shows comparison of properties for solely $\mathrm{NaCl}, \mathrm{NaCl}$ with $0.013 \mathrm{~mol} / \mathrm{L} \mathrm{KCl}$, and $\mathrm{NaCl}$ with $46 \mathrm{mmol} / \mathrm{L}$ of combined $\mathrm{KCl}$, urea, and lactic acid. $\mathrm{KCl}$ with concentration of $0.013 \mathrm{~mol} / \mathrm{L}$ does not alter the dielectric constant of $\mathrm{NaCl}$ solutions but does increase the conductivity. With $46 \mathrm{mmol} / \mathrm{L}$ of combined $\mathrm{KCl}$, urea, and lactic acid, $\mathrm{NaCl}$ solutions show changes in properties, such as decrease in dielectric constant and increase in conductivity. Figure 13 shows comparison of properties for solely $\mathrm{KCl}, \mathrm{KCl}$ with $0.1 \mathrm{~mol} / \mathrm{L} \mathrm{NaCl}$, and $\mathrm{KCl}$ with $118 \mathrm{mmol} / \mathrm{L}$ of combined $\mathrm{NaCl}$, urea, and lactic acid. After adding $0.1 \mathrm{~mol} / \mathrm{L}$ of $\mathrm{NaCl}$, the properties of the $\mathrm{KCl}$ solutions change. On the other hand, adding lactic acid and urea with $0.1 \mathrm{~mol} / \mathrm{L}$ of $\mathrm{NaCl}$ show increased conductivity and similar permittivity when compared to mixtures of $\mathrm{KCl}$ and $0.1 \mathrm{~mol} / \mathrm{L} \mathrm{NaCl}$.

In a large number of wearable devices and biosensors, the sensing decision depends on recording changes in electrical properties of tested solutions and biofluids. Thus, it is crucial to record and analyze the variations of complex permittivity values with frequency. These values and trends would help in designing biosensors with high sensitivity for sweat monitoring applications. Moreover, the above measurements verify that $\mathrm{NaCl}$, a dominant sweat component [10-15], has greatest effect on changing dielectric properties for sweat mixtures. 


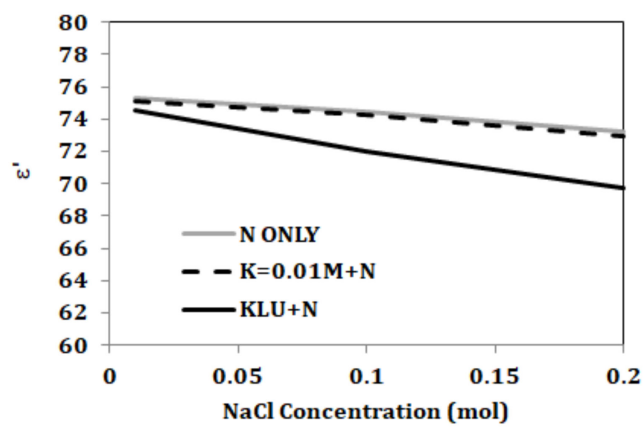

(a)

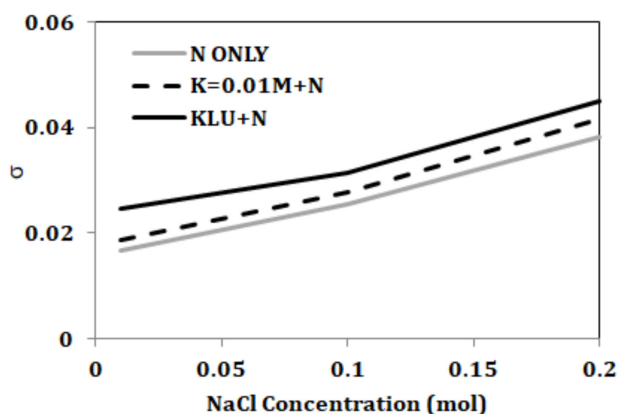

(b)

Figure 12. Measured (a) real part of complex permittivity $\left(\varepsilon^{\prime}\right)$ and $(\mathbf{b})$ conductivity versus concentration at $2.45 \mathrm{GHz}$ for aqueous solutions of $\mathrm{NaCl}, \mathrm{NaCl}$ with $\mathrm{K}=0.013 \mathrm{~mol} / \mathrm{L}, \mathrm{NaCl}$ with $\mathrm{K}=0.01 \mathrm{~mol} / \mathrm{L}$, $\mathrm{L}=0.02 \mathrm{~mol} / \mathrm{L}$, and $\mathrm{U}=0.01 \mathrm{~mol} / \mathrm{L}$ ("M" refers to $\mathrm{mol} / \mathrm{L}$ ).

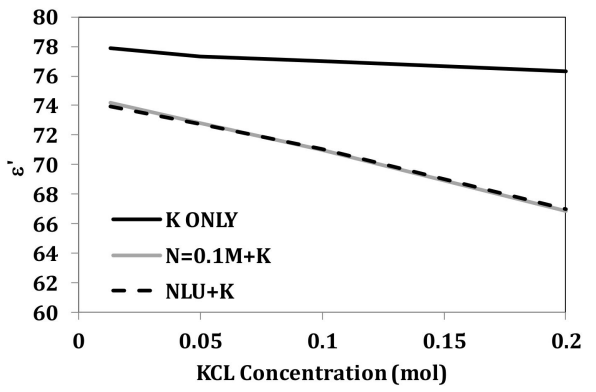

(a)

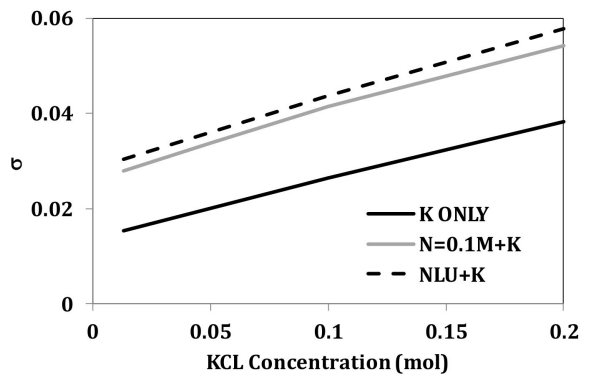

(b)

Figure 13. Measured (a) real part of complex permittivity $\left(\varepsilon^{\prime}\right)$ and $(\mathbf{b})$ conductivity versus concentration at $2.45 \mathrm{GHz}$ for aqueous solutions of $\mathrm{KCl}, \mathrm{KCl}$ with $\mathrm{N}=0.1 \mathrm{~mol} / \mathrm{L}, \mathrm{KCl}$ with $\mathrm{N}=0.1 \mathrm{~mol} / \mathrm{L}, \mathrm{L}=0.02 \mathrm{~mol} / \mathrm{L}$, and $\mathrm{U}=0.01 \mathrm{~mol} / \mathrm{L}$ ("M" refers to $\mathrm{mol} / \mathrm{L}$ ).

\section{Conclusions}

This paper provides a novel set of measurements to literature indicating solutions of biologically relevant concentrations of $\mathrm{NaCl}, \mathrm{KCl}$, urea, lactic acid, and their mixtures in the band of $1-20 \mathrm{GHz}$, at temperature of $23{ }^{\circ} \mathrm{C}$, with ionic concentrations in the range of $0.01-1.7 \mathrm{~mol} / \mathrm{L} . \mathrm{NaCl}, \mathrm{KCl}, \mathrm{urea}$, and lactic acid represent the four major sweat components. Most of the reported literature examines properties of solutions of single components, specifically $\mathrm{NaCl}$ or $\mathrm{KCl}$. However, mixtures of the four major sweat components are studied in detail for the first time in literature. The data presented in this study will allow understanding of microwave interaction with biological tissues, designing and testing new sensors, wearable devices, and therapeutic technologies.

Moreover, this paper presents a novel set of data indicating frequency-dependent electrical properties of artificial sweat (representing normal and hydrated states) and the effect of changing $\mathrm{pH}$ level on measured electrical properties. Measured dielectric properties of artificial sweat at both states are fitted using Cole-Cole model. The model parameters describing artificial sweat mixtures are also calculated for the first time in literature in this paper. Additional testing using mixtures of artificial sweat components linked changes in dielectric properties of artificial sweat with varying $\mathrm{NaCl}$ concentrations in comparison to property changes obtained when concentrations of other sweat electrolytes were varied (e.g., potassium chloride $(\mathrm{KCl})$, urea, and lactic acid). These data are of highly relevance in designing and testing hydration and sweat monitoring devices. 
The data presented in paper are not limited to hydration monitoring but may find application in understanding microwave interactions with human tissues and designing and testing of biosensors and consumer products.

Author Contributions: Conceptualization, A.R.E. and E.C.F.; methodology, A.R.E.; software, A.R.E. and S.T.; validation, A.R.E. and S.T.; formal analysis, A.R.E.; investigation, A.R.E.; resources, E.C.F.; data curation, A.R.E. and S.T.; writing —original draft preparation, A.R.E.; writing—review and editing, E.C.F.; visualization, A.R.E. and E.C.F.; supervision, E.C.F.; project administration, E.C.F.; and funding acquisition, E.C.F. All authors have read and agreed to the published version of the manuscript.

Funding: This research was funded Vice-President (Research) Strategic Funding at the University of Calgary and the Natural Sciences and Engineering Research Council of Canada (Discovery Grants program).

Conflicts of Interest: The authors declare no conflicts of interest.

\section{References}

1. Gulich, R.; Köhler, M.; Lunkenheimer, P.; Loidl, A. Dielectric spectroscopy on aqueous electrolytic solutions. Radiat. Environ. Biophys. 2009, 48, 107-114. [CrossRef] [PubMed]

2. Peyman, A.; Gabriel, C.; Grant, E.H. Complex permittivity of sodium chloride solutions at microwave frequencies. Bioelectromagnetics 2007, 28, 264-274. [CrossRef] [PubMed]

3. Nörtemann, K.; Hilland, J.; Kaatze, U. Dielectric Properties of Aqueous NaCl Solutions at Microwave Frequencies. J. Phys. Chem. A 1997, 101, 6864-6869. [CrossRef]

4. Romanov, A.N. Dielectric properties of human sweat fluid in the microwave range. Biophysics 2010, 55, 473-476. [CrossRef]

5. Tricoli, A.; Nasiri, N.; De, S. Wearable and Miniaturized Sensor Technologies for Personalized and Preventive Medicine. Adv. Funct. Mater. 2017, 27, 1605271. [CrossRef]

6. Liu, Y.; Wang, H.; Zhao, W.; Zhang, M.; Qin, H.; Xie, Y.; Liu, Y.; Wang, H.; Zhao, W.; Zhang, M.; et al. Flexible, Stretchable Sensors for Wearable Health Monitoring: Sensing Mechanisms, Materials, Fabrication Strategies and Features. Sensors 2018, 18, 645. [CrossRef]

7. White Papers-Pickering Test Solutions . Available online: https://www.pickeringtestsolutions.com/whitepapers/ (accessed on 2 April 2020).

8. Midander, K.; Julander, A.; Kettelarij, J.; Lidén, C. Testing in artificial sweat-Is less more? Comparison of metal release in two different artificial sweat solutions. Regul. Toxicol. Pharmacol. 2016, 81, 381-386. [CrossRef]

9. Brennan, D.; Galvin, P. Flexible substrate sensors for multiplex biomarker monitoring. MRS Commun. 2018, 8, 627-641. [CrossRef]

10. Callewaert, C.; Buysschaert, B.; Vossen, E.; Fievez, V.; Van de Wiele, T.; Boon, N. Artificial sweat composition to grow and sustain a mixed human axillary microbiome. J. Microbiol. Methods 2014, 103, 6-8. [CrossRef]

11. Liu, G.; Alomari, M.; Sahin, B.; Snelgrove, S.E.; Edwards, J.; Mellinger, A.; Kaya, T. Real-time sweat analysis via alternating current conductivity of artificial and human sweat. Appl. Phys. Lett. 2015, 106, 133702. [CrossRef]

12. Liu, G.; Ho, C.; Slappey, N.; Zhou, Z.; Snelgrove, S.E.; Brown, M.; Grabinski, A.; Guo, X.; Chen, Y.; Miller, K. A wearable conductivity sensor for wireless real-time sweat monitoring. Sens. Actuators B Chem. 2016, 227, 35-42. [CrossRef]

13. Hoekstra, R.; Blondeau, P.; Andrade, F.J. IonSens: A Wearable Potentiometric Sensor Patch for Monitoring Total Ion Content in Sweat. Electroanalysis 2018, 30, 1536-1544. [CrossRef]

14. Baker, L.B. Sweating Rate and Sweat Sodium Concentration in Athletes: A Review of Methodology and Intra/Interindividual Variability. Sports Med. 2017, 47, 111-128. [CrossRef] [PubMed]

15. Morgan, R.M.; Patterson, M.J.; Nimmo, M.A. Acute effects of dehydration on sweat composition in men during prolonged exercise in the heat. Acta Physiol. 2004, 182, 37-43. [CrossRef] [PubMed]

16. Schazmann, B.; Morris, D.; Slater, C.; Beirne, S.; Fay, C.; Reuveny, R.; Moyna, N.; Diamond, D. A wearable electrochemical sensor for the real-time measurement of sweat sodium concentration. Anal. Methods 2010, 2, 342-348. [CrossRef] 
17. Bandodkar, A.J.; Molinnus, D.; Mirza, O.; Guinovart, T.; Windmiller, J.R.; Valdés-Ramírez, G.; Andrade, F.J.; Schöning, M.J.; Wang, J. Epidermal tattoo potentiometric sodium sensors with wireless signal transduction for continuous non-invasive sweat monitoring. Biosens. Bioelectron. 2014, 54, 603-609. [CrossRef]

18. Rose, D.P.; Ratterman, M.E.; Griffin, D.K.; Hou, L.; Kelley-Loughnane, N.; Naik, R.R.; Hagen, J.A.; Papautsky, I.; Heikenfeld, J.C. Adhesive RFID sensor patch for monitoring of sweat electrolytes. IEEE Trans. Biomed. Eng. 2015, 62, 1457-1465. [CrossRef]

19. Gao, W.; Emaminejad, S.; Nyein, H.Y.Y.; Challa, S.; Chen, K.; Peck, A.; Fahad, H.M.; Ota, H.; Shiraki, H.; Kiriya, D. Fully integrated wearable sensor arrays for multiplexed in situ perspiration analysis. Nature 2016, 529, 509-514. [CrossRef]

20. Anastasova, S.; Crewther, B.; Bembnowicz, P.; Curto, V.; Ip, H.M.; Rosa, B.; Yang, G.-Z. A wearable multisensing patch for continuous sweat monitoring. Biosens. Bioelectron. 2017, 93, 139-145. [CrossRef]

21. Choi, D.-H.; Thaxton, A.; Jeong, I.C.; Kim, K.; Sosnay, P.R.; Cutting, G.R.; Searson, P.C. Sweat test for cystic fibrosis: Wearable sweat sensor vs. standard laboratory test. J. Cyst. Fibros. 2018, 17, e35-e38. [CrossRef]

22. Lamkaouchi, K.; Balana, A.; Delbos, G.; Ellison, W.J. Permittivity Measurements of Lossy Liquids in the Range 26-110 GHz. Meas. Sci. Technol. 2003, 14, 444-450. [CrossRef]

23. Maribo-Mogensen, B.; Kontogeorgis, G.M.; Thomsen, K. Modeling of Dielectric Properties of Aqueous Salt Solutions with an Equation of State. J. Phys. Chem. B 2013, 117, 10523-10533. [CrossRef]

24. Jensen, P.D.; Meaney, P.M.; Epstien, N.R.; Paulsen, K.D. Cole-Cole Parameter Characterization of Urea and Potassium for Improving Dialysis Treatment Assessment. IEEE Antennas Wirel. Propag. Lett. 2012, 11, 1598-1601. [CrossRef]

25. De los Reyes, R.; Heredia, A.; Fito, P.; De los Reyes, E.; Andrés, A. Dielectric spectroscopy of osmotic solutions and osmotically dehydrated tomato products. J. Food Eng. 2007, 80, 1218-1225. [CrossRef]

26. Eldamak, A.R.; Fear, E.C. Conformal and Disposable Antenna-Based Sensor for Non-Invasive Sweat Monitoring. Sensors 2018, 18, 4088. [CrossRef]

27. La Gioia, A.; Porter, E.; Merunka, I.; Shahzad, A.; Salahuddin, S.; Jones, M.; O’Halloran, M. Open-Ended Coaxial Probe Technique for Dielectric Measurement of Biological Tissues: Challenges and Common Practices. Diagnostics 2018, 8, 40. [CrossRef]

28. Kellomaki, T.; Whittow, W.G.; Heikkinen, J.; Kettunen, L. 2.4 GHz plaster antennas for health monitoring. In Proceedings of the 2009 3rd European Conference on Antennas and Propagation, Berlin, Germany, 23-27 March 2009; pp. 211-215.

29. Patel, M.; Wang, J. Applications, challenges, and prospective in emerging body area networking technologies. IEEE Wirel. Commun. 2010, 17, 80-88. [CrossRef]

30. Mercuri, M.; Soh, P.J.; Pandey, G.; Karsmakers, P.; Vandenbosch, G.A.E.; Leroux, P.; Schreurs, D. Analysis of an Indoor Biomedical Radar-Based System for Health Monitoring. IEEE Trans. Microw. Theory Tech. 2013, 61, 2061-2068. [CrossRef]

31. Soh, P.J.; Vandenbosch, G.A.E.; Mercuri, M.; Schreurs, D.M.M. Wearable Wireless Health Monitoring: Current Developments, Challenges, and Future Trends. IEEE Microw. Mag. 2015, 16, 55-70. [CrossRef]

32. Lai, Y.-L.; Chen, C.-L.; Chang, C.-H.; Hsu, C.-Y.; Lai, Y.-K.; Tseng, K.-K.; Chen, C.-C.; Zheng, C.-Y. An intelligent health monitoring system using radio-frequency identification technology. Technol. Health Care 2016, 24, S421-S431. [CrossRef]

33. Majumder, S.; Mondal, T.; Deen, M.J. Wearable Sensors for Remote Health Monitoring. Sensors 2017, 17, 130. [CrossRef] [PubMed]

(C) 2020 by the authors. Licensee MDPI, Basel, Switzerland. This article is an open access article distributed under the terms and conditions of the Creative Commons Attribution (CC BY) license (http://creativecommons.org/licenses/by/4.0/). 